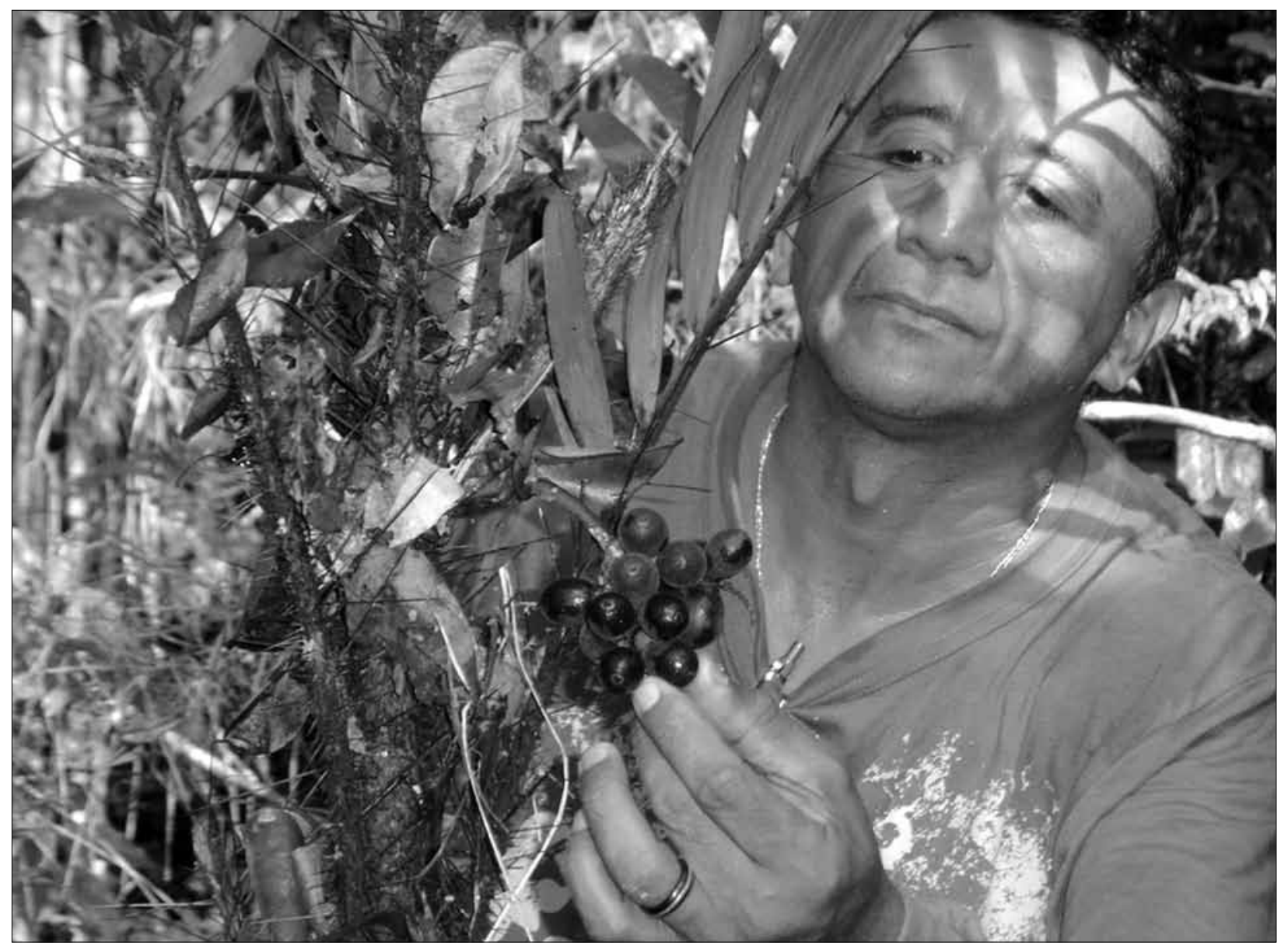

Figura 1. Samuel Almeida (1958-2011). 


\title{
O amazônida Samuel Soares de Almeida (1958-2011)
}

\author{
Ima Célia Guimarães Vieira', Ulisses Galatti', Dário Amaral' \\ 'Museu Paraense Emílio Goeldi. Belém, Pará, Brasil
}

Samuel Soares de Almeida (Figura 1), pesquisador do Museu Paraense Emílio Goeldi (MPEG), deixou nosso convívio em 1 de abril de 2011, após lutar contra problemas de saúde. Deixa um lastro de profícua produção científica, fruto de sua excepcional vitalidade e força de trabalho. Aos amigos e colegas, o dever de prosseguir com as várias frentes de trabalho que abriu.

Filho de Inácio Borges de Almeida e Ruth Soares de Almeida, nasceu em 15 de fevereiro de 1958, na cidade de Belém, Pará. Primogênito de sete irmãos, sua infância, marcada pelo afeto materno e pelos rigores de um pai evangélico, deu ensejo a um homem forte e responsável trabalhador. A morte precoce de sua mãe, quando Samuel contava com apenas 15 anos, delimita e precipita sua entrada na vida adulta. Samuel assume a responsabilidade pelo irmão menor e depois, já casado, reúne as irmãs que haviam sido entregues aos cuidados de parentes próximos.

Muito reservado sobre sua vida pessoal, construiu, ao lado de Maria Dinair Cristo de Alameida (Figura 2), um

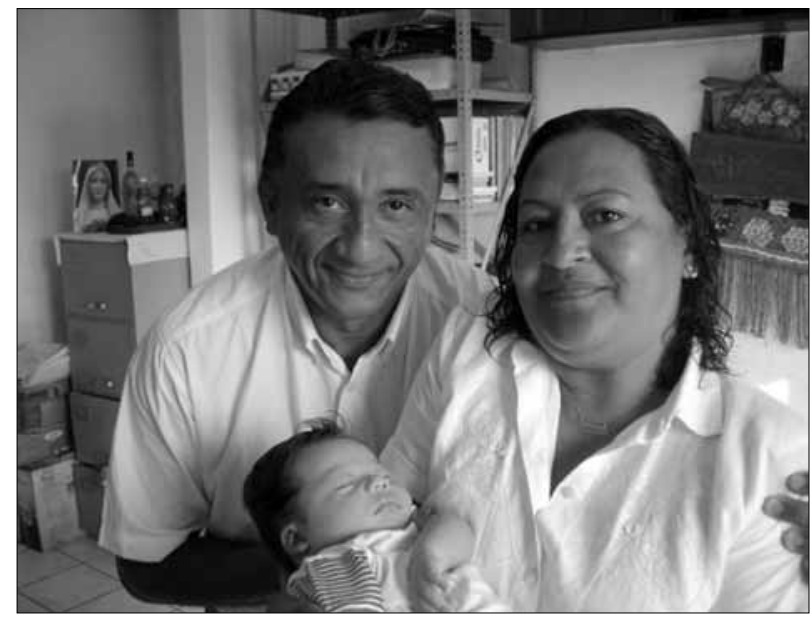

Figura 2. Samuel e Dinair com o netinho Pedro, filho de Jorge Nunes. Fonte: Arquivo familiar. lar amoroso e solidário, onde criou seus queridos filhos Jorge, Ruth, Everton e Samuel, que o brindaram com os netinhos Pedro, Otávio, Beatriz, Helen Tiago, Gabriel e Felipe. Embora discreto, percebíamos claramente que a vida era melhor se eles estivessem por perto.

Dos anos de sua formação, sabemos que concluiu o curso primário na Escola Dr. Felisberto Camargo e o ensino médio na Escola Orlando Bitar, em Belém. No ano de 1977, Samuel ingressou no Museu Goeldi para trabalhar como secretário do eminente botânico João Murça Pires. Logo depois, em 1981, ingressou no curso de Agronomia, na Faculdade de Ciências Agrárias do Pará, atual Universidade Federal Rural da Amazônia (UFRA), concluído em 1985. Até 1987, quando foi nomeado pesquisador na Coordenação de Botânica do Museu Goeldi, trabalhou como Técnico em Desenvolvimento.

Em 1989, sob a orientação da Dra. Judy Rankin-deMerona, concluiu seu mestrado em Ciências Biológicas no Programa de Pós-graduação em Biologia Tropical e Recursos Naturais (área de concentração Ecologia), no Instituto Nacional de Pesquisas da Amazônia (INPA), com o estudo "Clareiras Naturais na Amazônia Central: abundância, distribuiç̧ão, estrutura e aspectos da colonização vegetal". Em 1995, iniciou o doutorado na Universidade Estadual de Campinas (UNICAMP), sob a supervisão do Dr. Flávio Antonio M. dos Santos, onde chegou a cumprir todas as disciplinas do programa e a viajar para o Reino Unido, buscando complementar sua formação, porém, por motivos de ordem pessoal, não concluiu a tese. Em 2007, por obstinada vontade, retomou o acalentado projeto de Doutorado na Universidade Federal Rural da Amazônia, sob a orientação da Dra. Izildinha Miranda. Para esse projeto de doutorado, desenvolvia um importante estudo

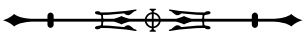


sobre "Diversidade florística e estratégias de sucessão em vegetação secundária do nordeste do estado do Pará".

Sabemos que sua vida acadêmica foi muito rica e envolveu diversificada atividade de pesquisa, além de também desenvolver projetos de extensão e executar tarefas administrativas. Samuel assumiu interinamente, em diferentes ocasiões na década de 1990, a chefia do Departamento de Botânica e foi coordenador da Estação Científica Ferreira Penna (ECFPn), em Caxiuanã, no período de outubro de 2001 a abril de 2003. Fazia questão de colaborar com as ações institucionais e elaborou diversas notas técnicas, pareceres, avaliações de projetos e ações governamentais, participando ativamente dos fóruns de discussão sobre ciência, tecnologia e meio ambiente na Amazônia e no Brasil. Era procurado e prestou consultorias a várias empresas e agências do governo nas áreas de Botânica e Conservação Ambiental. Em reuniões científicas, gostava de lembrar a todos que "promover o estudo sistemático desse universo verde que é a Amazônia é uma tarefa que requer o recrutamento de centenas de pesquisadores taxonomistas, sistematas, ecólogos, morfologistas, anatomistas, fisiologistas, geneticistas, agrônomos, entre outros".

Como pesquisador, Samuel se especializou na área de ecologia, embora conhecesse profundamente sistemática e fitogeografia. A vasta produção escrita, entre artigos publicados em revistas científicas, livros e anais de conferências nacionais e internacionais, o coloca como fonte de leitura obrigatória e preciosa fonte de dados, especialmente pelo amplo espectro de sua atuação. Entre suas contribuições científicas na área de Ecologia da Floresta Amazônica, incluem-se 22 publicações recentes no âmbito da Rede Amazônica de Inventários Florestais (RAINFOR), tendo como base as parcelas permanentes que estabeleceu em Caxiuanã.

Suas contribuições, tanto para o conhecimento botânico e da ecologia da Amazônia como para a formação de recursos humanos, são de enorme relevância. Samuel, em seus estudos sobre a ecologia da floresta, não perdia de vista a equação homem, ambiente e plantas, como muito bem colocou no título de seu blog ("Ecologia da Floresta Amazônica: ambiente, gente \& plantas")', que poucos conheciam.

A capacidade de liderança na área à qual se dedicou é inquestionável, tendo em vista os projetos que coordenou e os intercâmbios e colaborações que manteve ao longo de sua carreira. Cabe aqui destacar a frutífera atuação de Samuel em dois domínios, um relacionado à sua pesquisa acadêmica, centrada na ecologia vegetal, com profundas implicações em políticas públicas, e outro na formação e capacitação de recursos humanos, em diversos níveis, inclusive no treinamento de líderes comunitários e parataxonomistas, além dos cursos de campo que promovia com professores da UFRA em Caxiuanã (Figuras 3-6).

Coordenou e liderou o Projeto Avançado das Redes Científicas na Amazônia (PARAMA), voltado para a construção e fortalecimento da cooperação latino-americana com os parceiros europeus. Esta ação permitiu o desenvolvimento de massa crítica, de técnicas de monitoramento e o entendimento do papel dos ecossistemas amazônicos nas mudanças climáticas, na manutenção da biodiversidade e os efeitos das mudanças globais na floresta amazônica. A partir do treinamento no âmbito do PARAMA, liderado por Samuel, a participação de pesquisadores latino-americanos nas Redes RAINFOR, coordenadas pelos doutores Oliver Philips e Yadvinder Malhi, das Universidades de Leeds e de Oxford, respectivamente, e na Rede Amazonian Tree Diversity Network (ATDN), sob a coordenação do Dr. Hans Steege, da Universidade de Utrecht, tornou-se muito mais forte.

Os principais estudos de Samuel Almeida estavam voltados para a ecologia de populações e comunidades, manejo e conservação de ecossistemas e botânica econômica, que podem ser divididos em cinco grandes linhas de contribuições:

O blog pode ser acessado no endereço eletrônico: http://ssalmeida.blog.uol.com.br/

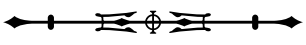


1) estudos florísticos e fitossociológicos de longo prazo de florestas de terra firme;

2) estudos de ecologia e dinâmica de várzeas amazônicas;

3) levantamento sobre plantas úteis;

4) estudos ecológicos como subsídios à conservação da biodiversidade;

5) estudos sobre estrutura, biomassa e ciclo do carbono de florestas.

Inúmeras expedições na Amazônia o levaram aos mais diferentes e longínquos recantos da maior floresta tropical do mundo. Alcançou os extremos na divisa com a Venezuela, subindo as serras do Surucucú e Parima, Roraima, oportunidade em que coletou e depositou no herbário do Museu Paraense Emílio Goeldi uma coleção da flora dessa região. O ano era 1991 e Samuel acompanhava a primeira Comissão Mista Demarcadora de Limites, do Ministério das Relações Exteriores. Investigou a região extra-brasileira da Amazônia, em 1992, na viagem à Bolívia em uma expedição apoiada pelo Programa das Nações Unidas para o Desenvolvimento (PNUD), por meio da Organização do Tratado de Cooperação Amazônica (OTCA). Nessa ocasião, percorreu mais de mil quilômetros de La Paz até Santa Cruz de La Sierra, realizando inventários ecológicos.

Em 1996, coordenou a equipe botânica que investigaria a vegetação de Rondônia, tendo visitado diferentes locais da região durante a elaboração do Zoneamento Ecológico Econômico do Estado.

As expedições, que muitas vezes se estendiam por várias semanas, estimulavam seu espírito investigativo sobre as diferentes tipologias vegetais da Amazônia. Entendeu - como poucos - as especificidades de habitats e da flora da Amazônia, e gerou uma série de publicações sobre os cerrados, vegetação litorânea de manguezal, florestas de várzea, florestas estacionais e florestas ombrófilas densas de terra firme.

Em recente depoimento, P. Meir e Y. Malhi consideraram que "o trabalho do Samuel consolidou e incluiu a investigação

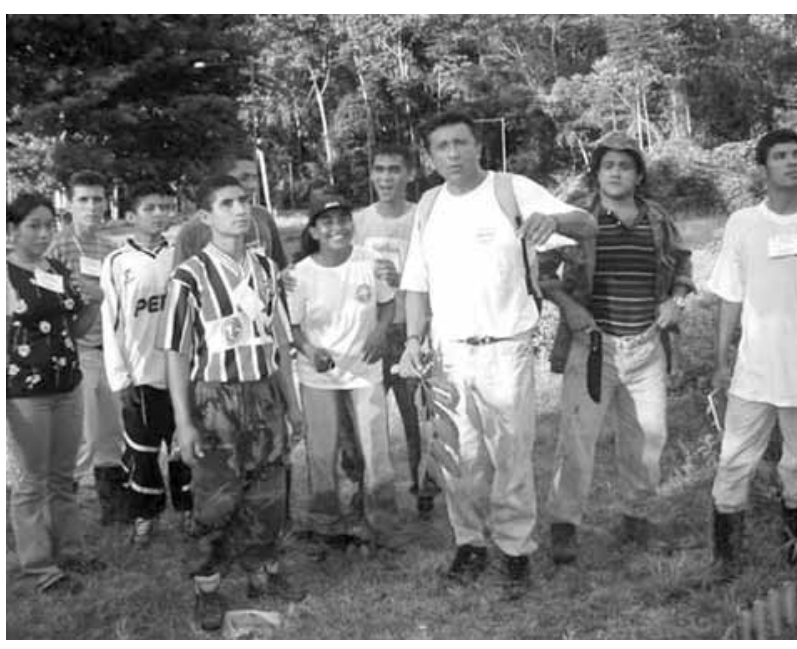

Figura 3. Em Caxiuanã, com alunos. Fonte: Arquivo familiar.

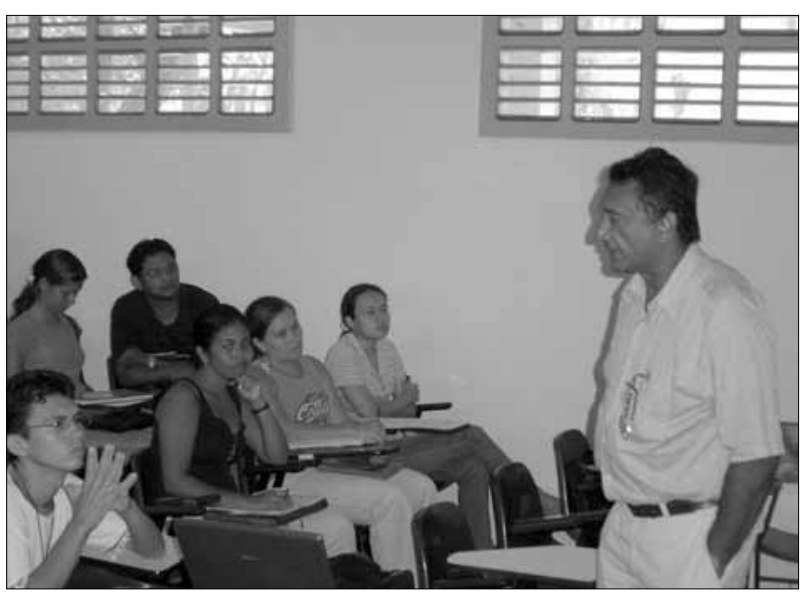

Figura 4. Em Caxiuanã, com alunos. Fonte: Arquivo familiar.

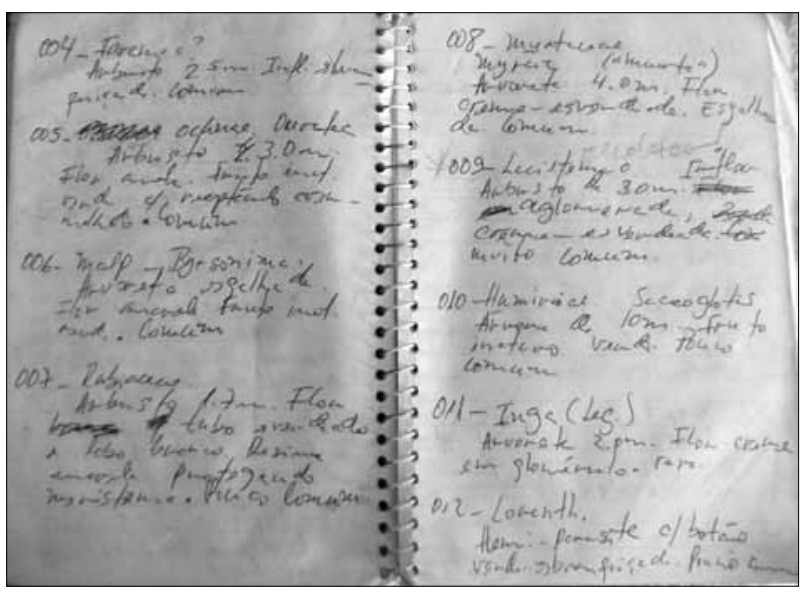

Figura 5. Cadernos de campo de Samuel Almeida. Fonte: Arquivo familiar.

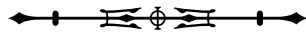




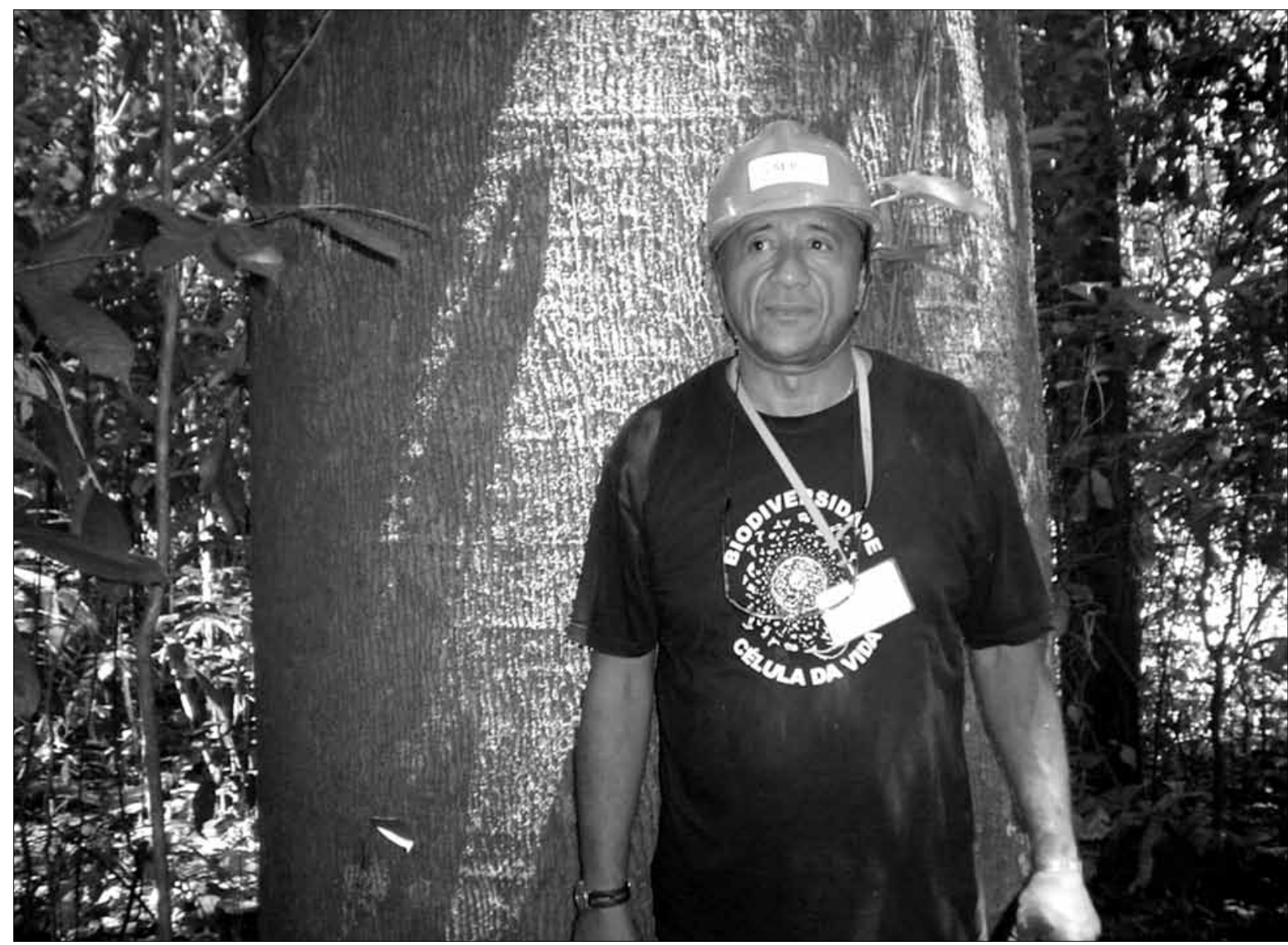

Figura 6. Em trabalho de campo. Fonte: Arquivo familiar.

florestal do MPEG em níveis de liderança internacional, e as parcelas a longo prazo que estabeleceu continuarão a ter um impacto no futuro".

Seu último projeto de grande envergadura foi o "Plantas do Futuro da Região Norte", que criou um banco de dados sobre as plantas úteis e listou 93 espécies do futuro, sobre as quais se tem razoável nível de informação. Samuel considerava que "o maior desafio para o ciclo dos produtos florestais não madeireiros era a inserção no mercado com garantia de qualidade" e, por isso, pensou o projeto como uma grande oportunidade da Amazônia deixar de ser apenas um "grande almoxarifado" de recursos naturais.

Samuel dedicou-se com entusiasmo a cumprir uma agenda de amplos inventários e foi tenaz em abordar, de maneira direta e com peculiar humor, problemas graves e complexos da região amazônica. Sempre preocupado com os destinos da região, costumava dizer que

\begin{abstract}
A vocação da Amazônia é florestal. A Amazônia não pode deixar de ser floresta em nome da madeira ou da pecuária. Se removermos toda a cobertura da floresta as populações futuras vão viver do quê? A vocação e fisionomia da Amazônia são marcadas pela floresta.
\end{abstract}

Quando ainda muito jovem, Samuel Almeida havia tido contato com a pesquisa agronômica no Instituto de Pesquisa Agropecuária do Norte (IPEAN), hoje Empresa Brasileira de Pesquisa Agropecuária (EMBRAPA Amazônia Oriental), por meio de seu pai, que era auxiliar do setor

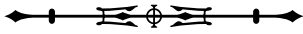


de entomologia. Certamente, sua vivência no IPEAN, onde morou, o inspirou como naturalista e estimulou os sentidos do futuro estudioso da ecologia amazônica. Sua intuição, aliada à boa disposição para o trabalho de campo o levaram a insights memoráveis, sempre apontando questões pontuais e elaborando pertinentes perguntas e respostas.

Samuel, "Samuca", para os amigos mais próximos, declarava-se um apaixonado pela região. Gostava especialmente de discutir política, futebol e contar histórias peculiares da vida amazônica. Samuel recolhia essas estórias com o gosto e a curiosidade de um colecionador. Em suas conversas sempre tinha um causo a contar. Era um atento e obstinado leitor. Quem conviveu com ele lembrará de seus sábios e criativos conselhos e dos textos filosóficos com que nos brindava quase que diariamente.

Nesse breve relato, como se pudéssemos estabelecer uma moldura, ressaltaríamos essencialmente a humildade e a maneira simples de ser alegre que lhe eram peculiares. Nosso Samuca não era um homem de bravatas, ao contrário, em sua fala mansa, deixava antever um homem gentil, capaz de um convívio amigo e agradável, sem esconder sua índole valorosa e altiva. Ao acompanhá-lo em campo, era comum ouvir os alunos comentarem reclamando sobre seu passo largo e forte, que buscavam seguir ofegantes e agradeciam quando pausado para a verificação mais detalhada de alguma espécie, mas que os conduziam, invariavelmente, a andar entre 20 a $30 \mathrm{~km}$ por trilha.
Assim, Samuel se manteve até o fim: atento e a passos largos. Antecipando a partida, refletiu melancolicamente:

\begin{abstract}
Eujá estive pelo menos duas vezes bem próximo da morte. Dá uma angústia e melancolia em deixar esse mundo e todas as coisas boas que a gente construiu nessa caminhada terrena. Engraçado que apesar de ter pouca coisa, não me lembrei desse lado. Me lembrei das pessoas amigas, das boas conversas, dos locais que gosto de ir, dos filhos, da esposa. Aí vem a dúvida do reencontro. Acaba tudo ou não? As religiões nos consolam com o mito da vida eterna, e são quase todas (cristãs, budistas, muçulmanas, judias, hindus etc.). Todas tratam desse resgate eis uma questão indecifrável que os materialistas já definiram (Samuel Almeida, 29/04/2009).
\end{abstract}

Entretanto, a reflexão não inibiu a ação: Samuel trabalhou atendendo às mais diferentes solicitações até o dia 30 de março de 2011. Sobre sua mesa, os trabalhos e agenda de um homem produtivo, atribulado com mil solicitações, assaltado no auge da vida por um repouso anunciado, mas que aguardava, esperançoso, o adiamento. Em nosso adeus, os versos de Cartola, compositor de sua predileção, que oferece a medida do que esperamos:

\section{A Canção de Saudade}

Tudo de alegrias e de tristezas conheci Coisas do amor e do sofrer eu já senti Nada me transforma a alegria de viver Vêr a noite vir e sorrir ao sol nascer Vivo esperando o novo dia Que irá trazer a luz que sempre ficará 
